\title{
Norcantharidin triggers cell death and DNA damage through S-phase arrest and ROS-modulated apoptotic pathways in TSGH 8301 human urinary bladder carcinoma cells
}

\author{
CHIEN-CHIH YU ${ }^{1}$, FANG-YU KO ${ }^{2}$, CHUN-SHU YU ${ }^{1}$, CHIN-CHUNG LIN ${ }^{3}$, \\ YI-PING HUANG ${ }^{4}$, JAI-SING YANG ${ }^{5}$, JING-PIN LIN ${ }^{6}$ and JING-GUNG CHUNG ${ }^{7,8}$ \\ ${ }^{1}$ School of Pharmacy, China Medical University, Taichung 404; ${ }^{2}$ Department of Cosmeceutics, China Medical \\ University, Taichung; ${ }^{3}$ Department of Chinese Medicine, Fong-Yuan Hospital, Department of Health, Executive \\ Yuan, Taichung 420; ${ }^{4}$ Department of Physiology, China Medical University, Taichung 404; ${ }^{5}$ Department \\ of Pharmacology, China Medical University, Taichung 404; ${ }^{6}$ School of Chinese Medicine, China Medical \\ University, Taichung; ${ }^{7}$ Department of Biological Science and Technology, China Medical University, \\ Taichung 404; ${ }^{8}$ Department of Biotechnology, Asia University, Taichung 413, Taiwan, R.O.C.
}

Received February 22, 2012; Accepted April 27, 2012

DOI: $10.3892 /$ ijo.2012.1511

\begin{abstract}
Norcantharidin (NCTD) is one of the ingredients of blister beetles which have been used in Chinese medicine for a long time. The purpose of this study was to investigate the inhibitory effects of NCTD on TSGH 8301 human bladder cancer cells in vitro and the mechanisms through which it exerts its anticancer action. Cell morphological analysis was performed using a phase-contrast microscope. The percentage of viable cells, cell cycle distribution, sub-G1 phase (apoptosis), reactive oxygen species (ROS) production and the levels of mitochondrial membrane potential $\left(\Delta \Psi_{m}\right)$ were analyzed by flow cytometry. DNA condensation and damage were determined by DAPI staining and comet assay. Apoptosisassociated protein level changes in TSGH 8301 cells following exposure to NCTD were examined, measured and determined by western blotting. Analysis of protein translocation was conducted by immunostaining and confocal laser microscopy. The results indicated that NCTD promoted cytotoxic effects, including the induction of cell morphological changes and the decrease in the percentage of viability, the induction of S-phase arrest as well as sub-G1 phase (apoptosis) in TSGH 8301 cells. The activities of caspase- 3 and -9 were upregulated following NCTD treatment. Western blotting indicated that NCTD
\end{abstract}

Correspondence to: Professor Jing-Gung Chung, Department of Biological Science and Technology, China Medical University, no. 91, Hsueh-Shih Road, Taichung 40402, Taiwan, R.O.C.

E-mail: jgchung@mail.cmu.edu.tw

Professor Jing-Pin Lin, School of Chinese Medicine, China Medical University, no. 91, Hsueh-Shih Road, Taichung 40402, Taiwan, R.O.C.

E-mail:.jplin@mail.cmu.edu.tw

Key words: norcantharidin, human bladder cancer TSGH 8301 cells, apoptosis, mitochondria upregulated Fas, FasL, Bax, Bid, cytochrome $c$, caspase-3, -8 and -9 that led to the induction of apoptosis through the Fas extrinsic pathway. Furthermore, NCTD induced AIF and Endo $G$ that were released from mitochondria to induce apoptosis through the mitochondrial-independent pathway. NCTD upregulated ROS production, downregulated $\Delta \Psi_{m}$ and ERK, JNK, p38 protein kinases in TSGH 8301 cells. These findings suggest that NCTD triggers apoptosis in TSGH 8301 human bladder cancer cells via the Fas receptor, activation of the caspse-8, -9 and -3, mitochondrial-dependent and -independent pathways. NCTD may be useful for developing new therapeutic regimens for the treatment of bladder cancer.

\section{Introduction}

Bladder cancer is one of the leading causes of mortality in humans worldwide. Bladder cancer is the fourth most common malignancy in men and the ninth most common in women in United States (1). In Taiwan, about 3.2 per 100,000 individuals succumb to the disease annually, according to the 2010 report from the Department of Health, R.O.C. (Taiwan). Currently, the treatments for bladder cancer remain unsatisfactory, therefore, numerous studies have focused on finding or synthesizing new compounds and on investigating the molecular mechanisms of action from bioactive compounds in order to develop chemoprevented and/or therapeutic agents (2).

One of the best ways for anticancer agents to treat cancer is to induce cell apoptosis. The characteristic morphological and biochemical changes of apoptosis are mediated by a series of gene regulation and cell-signaling pathways, including the extrinsic pathway $(3,4)$ which is triggered via specific ligand and surface receptors CD95/Fas, tumor necrosis factor (TNF) and death receptors (3-5); the intrinsic pathway, which is induced via DNA damage, cellular distress, hypoxia and cytotoxic agents $(4,6)$; and the endoplasmic reticulum (ER) stress pathway via the interaction between the mitochondria and the ER (7). 
Mylabris (Chinese blistering beetle) such as Mylabris phalerata Pall. and M. cichorii Linn was mostly used in medicine and it is still used as a folk medicine today (8). The active constituent of mylabris is cantharidin (9). Norcantharidin (NCTD) is the demethylated analog of cantharidin isolated from natural blister beetles (10). NCTD induces apoptosis in hepatoma cells (11), inhibits tumor cell growth, invasion, and metastasis in nude mice bearing human gallbladder carcinoma (12) and it also induces cytotoxicity in HepG2 cells by apoptosis, which is mediated through reactive oxygen species (ROS) generation and the mitochondrial pathway (13). Furthermore, numerous studies have reported that NCTD inhibits angiogenesis and breast cancer cell line metastases without significant renal or liver toxicity $(10,14-18)$.

However, the inhibitory activities of NCTD against human bladder cancer cells remains unclear. In this study, we investigated the in vitro effects of NCTD on the growth of the human bladder cancer cell line TSGH 8301. We investigated the molecular mechanisms of action of NCTD on ROS production associated with the induction of apoptosis and its downstream targets.

\section{Materials and methods}

Chemicals and reagents. Norcantharidin, dimethyl sulfoxide (DMSO), potassium phosphates, propidium iodide (PI), Tris- $\mathrm{HCl}$, trypan blue and ribonuclease-A (RNase A), were obtained from Sigma-Aldrich Corp. (St. Louis, MO, USA). RPMI-1640 medium, L-glutamine, fetal bovine serum (FBS), penicillin-streptomycin, and trypsin-EDTA were obtained from Gibco/Life Technologies (Grand Island, NY, USA). Norcantharidin was prepared in DMSO and stored as small aliquots at $-20^{\circ} \mathrm{C}$. Anti-p21 (Cat. 05-345), anti-p53 (Cat. 04-241) and anti-Bax (Cat. 04-434) were bought from Merck Millipore (Bedford, MA, USA). The other primary antibodies used in this study were purchased from Santa Cruz Biotechnology, Inc. (Santa Cruz, CA, USA).

Cell culture. The TSGH 8301 human bladder carcinoma cells were purchased from the Food Industry Research and Development Institute (Hsinchu, Taiwan). TSGH 8301 cells were maintained on $75 \mathrm{~cm}^{2}$ tissue culture flasks with RPMI-1640 medium with $10 \% \mathrm{FBS}$ and $1.5 \mathrm{mM} \mathrm{L-glutamine} \mathrm{were} \mathrm{adjusted}$ to contain $1.5 \mu \mathrm{g} / \mathrm{ml}$ sodium bicarbonate and $1 \%$ penicillinstreptomycin (100 U/ml penicillin and $100 \mu \mathrm{g} / \mathrm{ml}$ streptomycin) and grown at $37^{\circ} \mathrm{C}$ under a humidified $5 \% \mathrm{CO}_{2}$ atmosphere (18).

Cell morphology, viability, cell cycle distribution and apoptosis assays. TSGH 8301 cells were seeded in a 12-well plate at a concentration of $2 \times 10^{5}$ cells/well overnight and were then incubated with $0,10,20,30,40$ and $50 \mu \mathrm{M}$ of NCTD at $37^{\circ} \mathrm{C}$, $5 \% \mathrm{CO}_{2}$ and $95 \%$ air for 24 and $48 \mathrm{~h}$. Cells were examined and photographed under a phase-contrast microscope at x200 for morphological changes. Then, cells in each well were harvested and stained with PI $(5 \mu \mathrm{g} / \mathrm{ml})$ and the total percentage of viable cells in all samples was measured by flow cytometry (Becton-Dickinson, San Jose, CA, USA), as previously described $(18,19)$. For cell cycle distribution and sub-G1 (apoptosis) determination, isolated cells from each treatment were fixed gently by putting $70 \%$ ethanol at $4^{\circ} \mathrm{C}$ overnight and then re-suspended in PBS containing $40 \mu \mathrm{g} / \mathrm{ml}$ PI and $0.1 \mathrm{mg} / \mathrm{ml}$ RNase and $0.1 \%$ Triton $\mathrm{X}-100$ in the dark for $30 \mathrm{~min}$ at $37^{\circ} \mathrm{C}$; the cells were then analyzed with a flow cytometer equipped with an argon ion laser at $488 \mathrm{~nm}$ wavelength $(18,19)$. In order to confirm whether or not NCTD induces cell morphological changes and decreases the total percentage of viable TSGH 8301 cells, cells were pretreated with NAC, and were then treated with NCTD and cell morphological changes and total viable cells were measured as described above.

DNA damage measured by DAPI staining and comet assay. Approximately $2 \times 10^{5}$ cells $/ \mathrm{ml}$ of TSGH 8301 cells in a 12-well plate were individually treated with $0,10,20,30,40$ and $50 \mu \mathrm{M}$ of NCTD for $24 \mathrm{~h}$. For DAPI staining, cells in each treatment were stained with DAPI (4,6-diamidino-2-phenylindole dihydrochloride), and were then examined and photographed using a fluorescence microscope as previously described (19-21). For the comet assay, cells from each treatment were harvested by centrifugation, isolated and examined for DNA damage using the comet assay as previously described (19-21).

Detections of ROS (reactive oxygen species), mitochondrial membrane potential $\left(\Delta \Psi_{m}\right)$ and caspase-3 activity in TSGH 8301 cells. Approximately $2 \times 10^{5}$ cells $/ \mathrm{ml}$ of TSGH 8301 cells were placed in a 12-well plate for $24 \mathrm{~h}$ and then individually treated with $20 \mu \mathrm{M}$ of NCTD for $0,12,24$, 48 and 72 h. Subsequently, cells from each treatment were harvested by centrifugation and re-suspended in $500 \mu \mathrm{l}$ of 2,7-Dichlorodihydrofluorescein diacetate (DCFH-DA) $(10 \mu \mathrm{M})$ for ROS, in $500 \mu \mathrm{l}$ of $\mathrm{DiOC}_{6}(1 \mu \mathrm{M})$ for $\Delta \Psi_{m}$ and in $500 \mu \mathrm{l}$ of PhiPhiLux-G1D2 substrate $(25 \mu \mathrm{M})$ for caspase-3 activity determination, as previously described (19-21). Cells from each treatment were incubated at $37^{\circ} \mathrm{C}$ for $30 \mathrm{~min}$ before being analyzed by flow cytometry as previously described (19-21), or cells in each treatment were pretreated with NAC and then treated with NCTD for $24 \mathrm{~h}$ before being harvested to measure the ROS and NAO productions, the levels of $\Delta \Psi_{m}$ and catalase expression.

Determination of cell cycle and apoptosis-associated proteins by western blotting. Approximately $5 \times 10^{5}$ cells of TSGH 8301 cells were maintained in a 6 -well plate and then treated with $20 \mu \mathrm{M}$ NCTD for $0,6,12,24,48$ and $72 \mathrm{~h}$. Cells from each treatment were harvested in tube with lysis buffer containing $40 \mathrm{mM}$ Tris- $\mathrm{HCl}$ (pH 7.4), 10 mM EDTA, $120 \mathrm{mM} \mathrm{NaCl}, 1 \mathrm{mM}$ dithiothreitol, $0.1 \%$ Nonidet P-40 and total proteins were quantified as previously described (19-21). Total proteins (30 $\mu \mathrm{g})$ from each treatment were individually loaded into the gel for western blot analysis and all samples were performed using $10 \%$ Tris-glycine-SDS-polyacrylamide gels for $30 \mathrm{~min}$. The proteins were then transferred to a nitrocellulose membrane by electroblotting (19-21). The transferred membranes were incubated with primary antibodies as follows: i) p27, p21 and p53; ii) caspase-8, -9 and -3; iii) Bax and Bid; iv) AIF, Endo $\mathrm{G}$ and cytochrome $c$; v) Fas and FasL; vi) p-ERK, JNK and p-p38 and were washed before being incubated with a secondary antibody for enhanced chemiluminescence (NEN Life Science Products, Inc, Boston, MA, USA) as previously described (19-21). Anti- $\beta$-actin (a mouse monoclonal antibody) was used as a loading control. 
$\mathbf{A}$
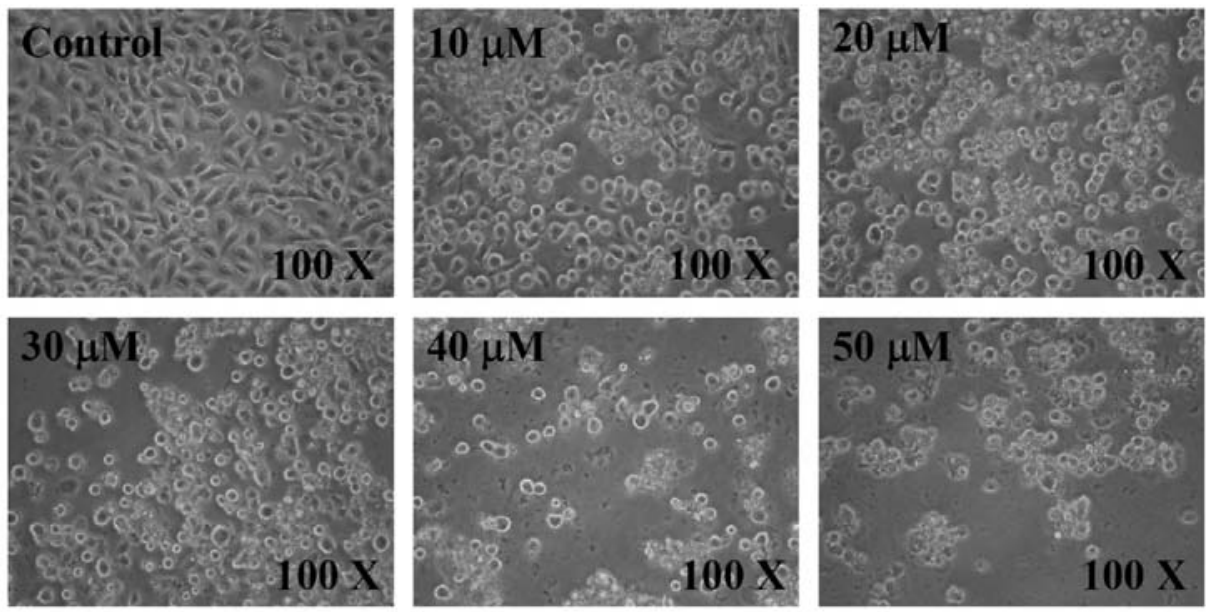

B
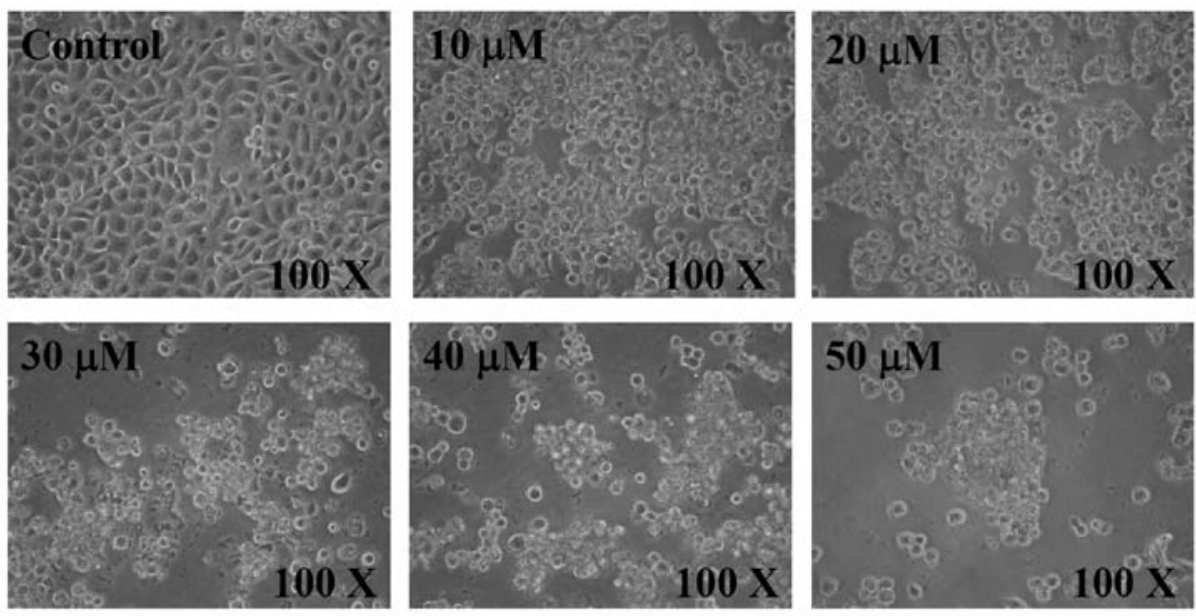

C

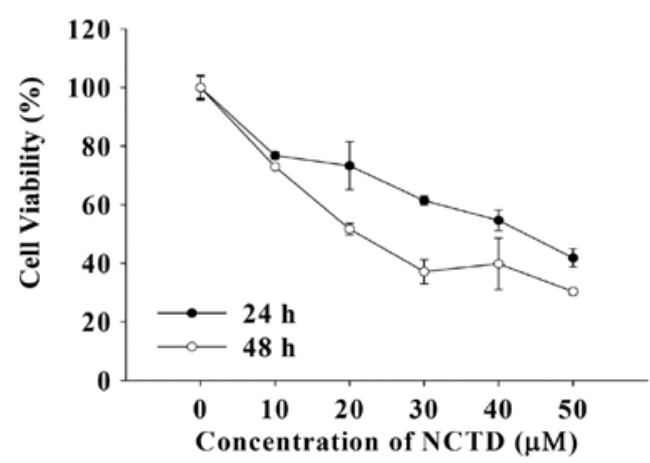

Confocal laser scanning microscopy shows protein translocation in TSGH 8301 cells. TSGH 8301 cells $\left(5 \times 10^{4}\right.$ cells/well) were cultured on 4-well chamber slides and were then treated with or without $20 \mu \mathrm{M}$ NCTD for $24 \mathrm{~h}$. Cells on the slides were fixed in $4 \%$ formaldehyde in PBS for $15 \mathrm{~min}$, permeabilized with $0.3 \%$ Triton-X 100 in PBS for $1 \mathrm{~h}$ with blocking of non-specific binding sites using $2 \%$ BSA as previously described (21). Primary antibodies to AIF and Endo G (1:100 dilution) (green fluorescence) were used to stain the fixed cells overnight and were then washed twice with PBS and stained with secondary antibody (FITC-conjugated goat anti-mouse IgG at 1:100 dilution), followed by DNA staining with mitotracker (red fluorescence) as previously described (21). All samples were photomicrographed and were obtained using a Leica TCS SP2 Confocal Spectral Microscope (21).
Figure 1. Norantharidin (NCTD) induced morphological changes and affected the viability of TSGH 8301 human bladder cancer cells. Cells in a 12-well plate were treated with $0,10,20,30,40$ and $50 \mu \mathrm{M}$ of NCTD for 24 and $48 \mathrm{~h}$ and were then examined and photographed for morphological changes (A and $\mathrm{B}$ ) by a phase-contrast microscope. (C) Cells were harvested to determine viability using a flow cytometric assay, as described in Materials and methods. Values show means \pm SD from three independent experiments.

Statistical analysis. The results in this study are shown as the mean \pm SD and the difference between the NCTD-treated and control groups were analyzed by Student's $t$-test; a probability of $\mathrm{P}<0.05$ was considered significant.

\section{Results}

Effects of NCTD on cell morphology, viability, cell cycle distribution and sub-G1 phase in TSGH 8301 cells. The effects of the growth inhibition of NCTD on TSGH 8301 cells were examined; the morphological changes were observed under a phase-contrast microscope, viability, cell cycle distribution and sub-G1 (apoptosis) were examined by flow cytometric assay and the results are shown in Fig. 1A-C and Fig. 2A and B. Increasing the concentrations of NCTD and/or the time 
A
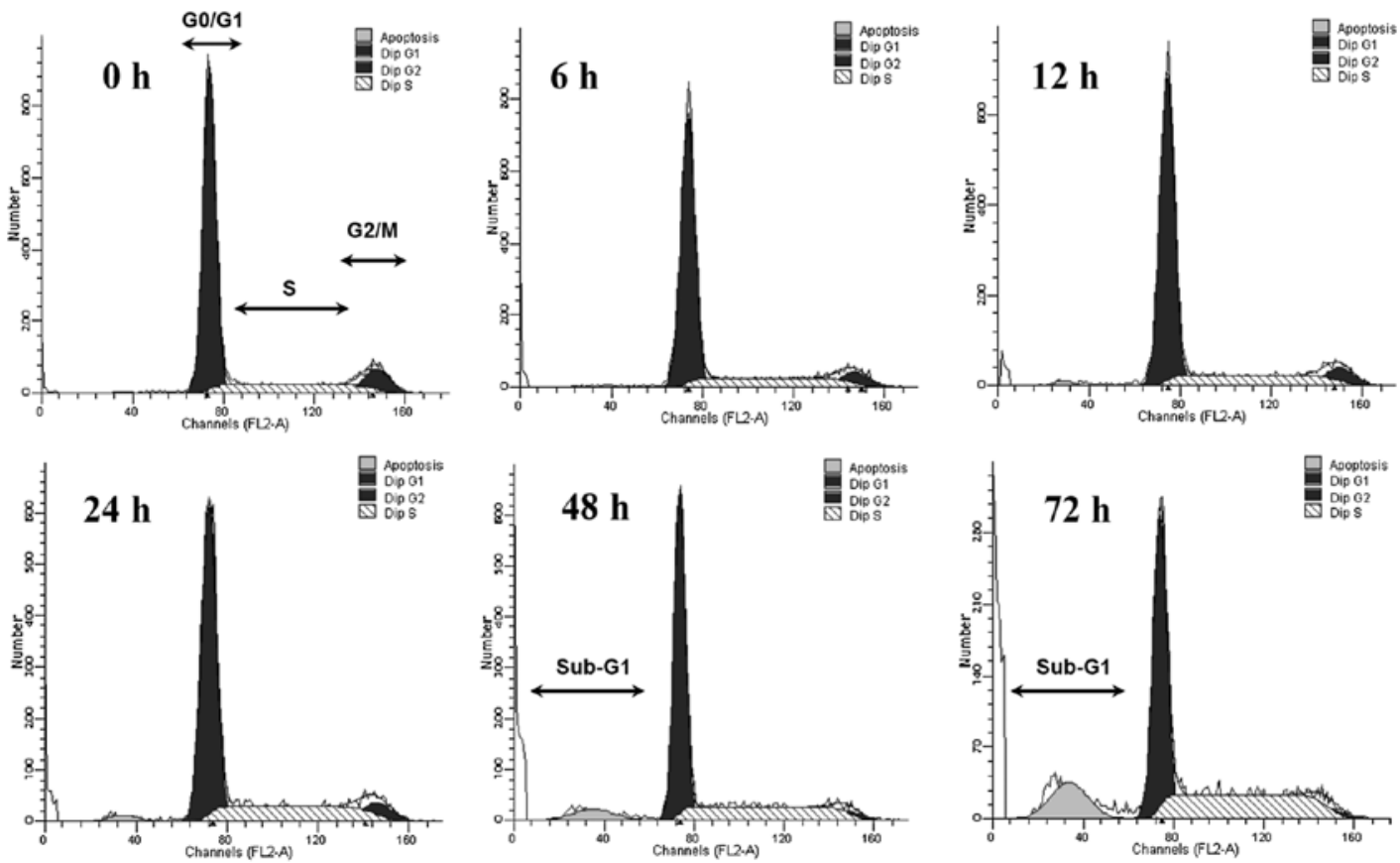

B

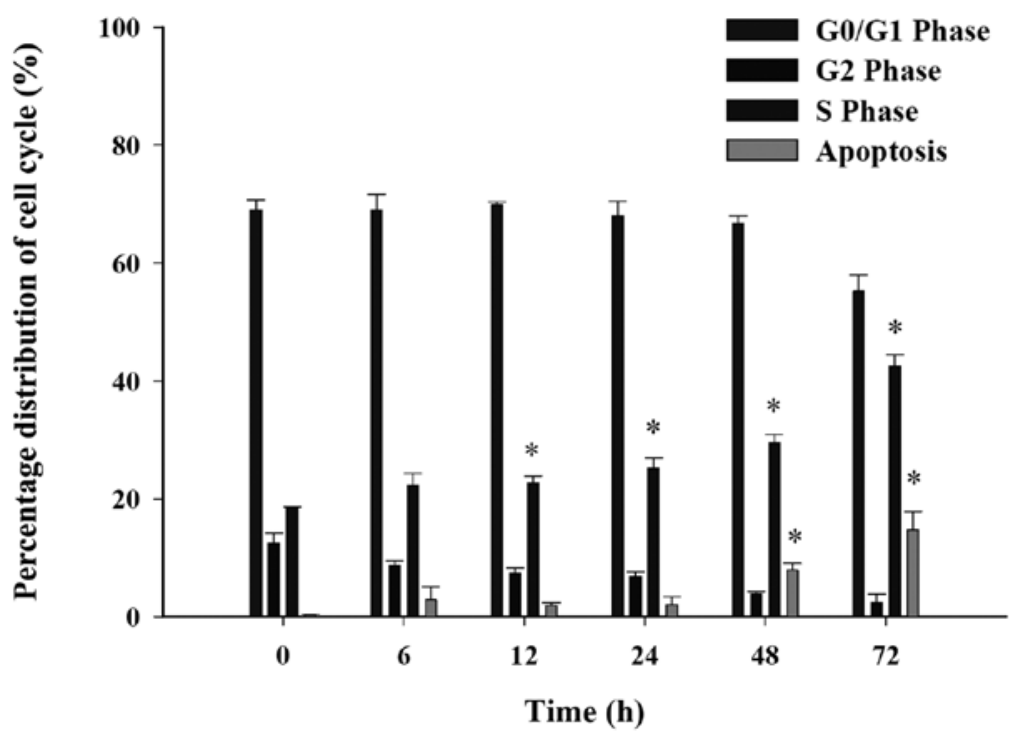

Figure 2. NCTD induced cell cycle arrest and sub-G1 in TSGH 8301 cells. Cells were treated with 0 and $20 \mu \mathrm{M}$ of NCTD for 0,6, 12, 24, 48 and 72 h and then harvested for examination of cell cycle distribution by flow cytometry, as described in Materials and methods. (A) representative profiles; (B) percentage of cell distribution. $\mathrm{P}<0.05$ indicates a statistically significant difference from the $0 \mathrm{~h}$ treatment (control group).

of incubation led to an increase in morphological changes (Fig. 1A and B) and a decrease in the percentage of viability (Fig. 1C). NCTD $(20 \mu \mathrm{M})$ significantly decreased by almost $48 \%$ the viable cells at $48 \mathrm{~h}$ treatment. Fig. $2 \mathrm{~A}$ and B show that TSGH 8301 cells were exposed to $20 \mu \mathrm{M}$ of NCTD for various intervals of time increased the percentage of cells in $\mathrm{S}$ phase in a time-dependent manner. Furthermore, the sub-G1 groups (apoptosis) also appeared in the cell cycle distribution and these effects are time-dependent.

Effects of NCTD on DNA condensation and damage in TSGH 8301 cells. The effects of NCTD on DNA damage of
TSGH 8301 cells were examined by comet assay and DAPI staining. The TSGH 3801 cells were treated with various concentrations of NCTD for $24 \mathrm{~h}$ and then isolated for DAPI staining and comet assay. The results are presented in Fig. 3A and B and indicate that NCTD induced DNA condensation and decreased the cell number (Fig. 3A) and also induced DNA damage (Fig. 3B) in TSGH 8301 cells.

Effects of NCTD on the levels of reactive oxygen species (ROS), mitochondrial membrane potential $\left(\Delta \Psi_{m}\right)$ and caspase-3 activity in TSGH 8301 cells. In order to examine whether or not NCTD triggers apoptosis via contributions from the ROS 

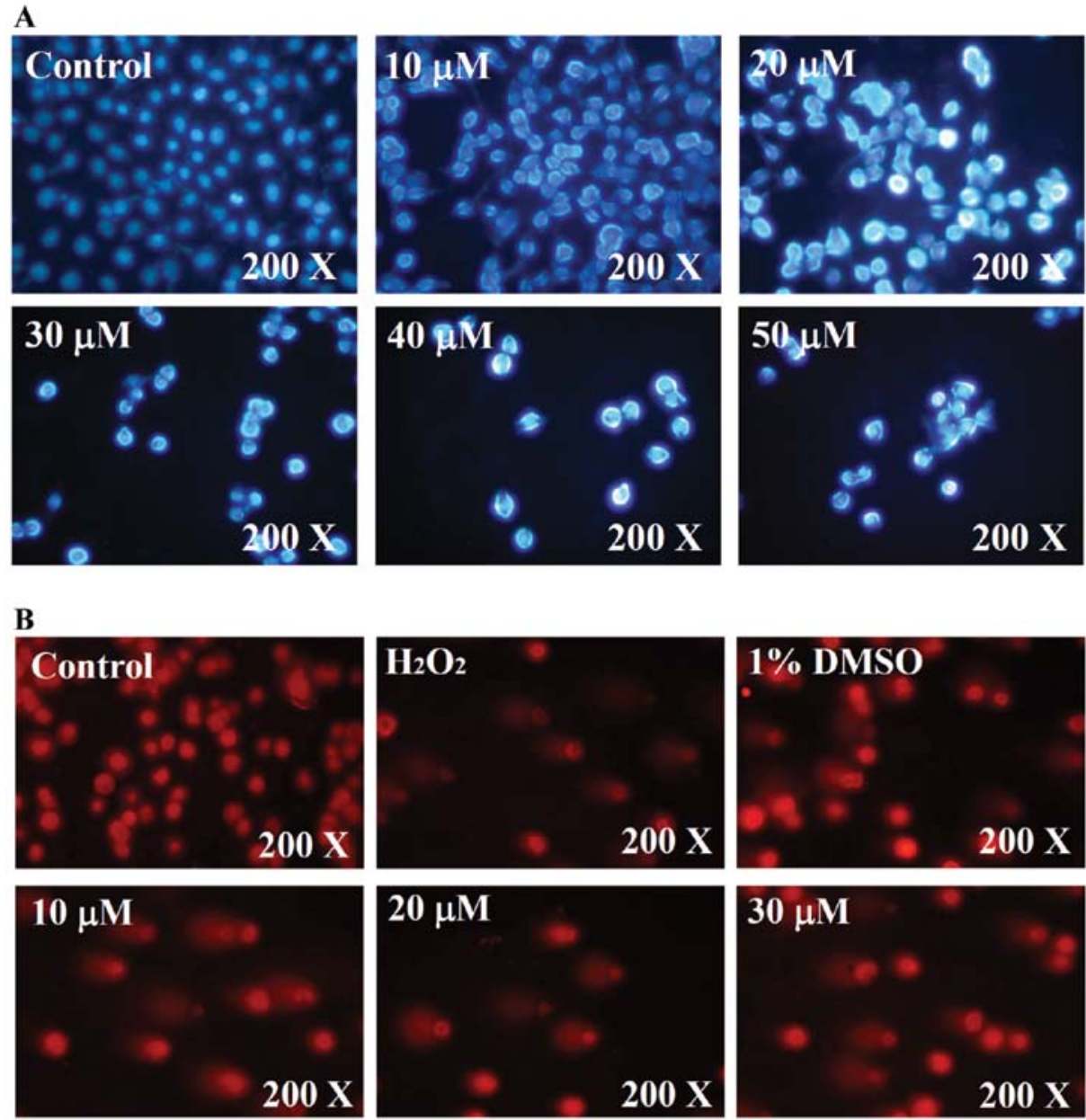

Figure 3. NCTD induced DNA condensation and damage in TSGH 8301 cells. Cells were treated with $0,10,20,30,40$ and $50 \mu \mathrm{M}$ of NCTD for $24 \mathrm{~h}$ and then cells from each well were harvested for examination of DNA damage by (A) DAPI staining, or (B) comet assay, as described in Materials and methods. Similar results were obtained in three independent experiments.

production, mitochondrial and caspase-3 pathway, TSGH 8301 cells were treated with $20 \mu \mathrm{M}$ NCTD for various time periods. The levels of ROS production, $\Delta \Psi_{m}$ and caspase-3 activity were measured and determined by flow cytometric assay (Fig. 4A-C). Fig. 3 shows NCTD increased the production of ROS (Fig. 4A) and decreased the levels of $\Delta \Psi_{\mathrm{m}}$ (Fig. 4B), compared with the control group. Fig. 4C also shows that NCTD induced the activity of caspase-3 in TSGH 8301 cells.

NAC pretreatment affects NCTD-induced morphological changes, viability, reactive oxygen species (ROS) production, the levels of mitochondrial membrane potential $\left(\Delta \Psi_{m}\right)$ and NAO and catalase productions in TSGH 8301 cells. To confirm the role of ROS in NCTD-induced cell death in TSGH 8301 cells, the cells were pretreated with ROS scavenger (N-acetyl cystein, NAC) and were then treated with $20 \mu \mathrm{M}$ NCTD for $24 \mathrm{~h}$. The cells were then examined for cell morphological changes (Fig. 5A), total percentage of viable cells (Fig. 5B), ROS production (Fig. 5C), the levels of $\Delta \Psi_{m}$ (Fig. 5D), and NAO production (Fig. 5E). Fig. 5 shows that after cells were pretreated with NAC, there was a decrease in cell morphological changes (Fig. 5A), an increase in the viable cell number (Fig. 5B), a decrease in the ROS production (Fig. 5C) and an increase in the levels of $\Delta \Psi_{m}$ (Fig. 5D), but no significant effect on NAO production in TSGH 8301 cells. Fig. 5F shows that TSGH 8301 cells following treatment with NCTD led to an increase in the catalase expression time-dependently.

Effects of NCTD on the associated protein levels of apoptosis in TSGH 8301 cells. In order to investigate NCTD-induced apoptosis through the possible signaling pathways in TSGH 8301 cells, the cells were treated with $20 \mu \mathrm{M}$ of NCTD for various time periods and the protein levels were analyzed by western blotting. Results are shown in Fig. 6, where NCTD increased the levels of p27, p21 and p53 (Fig. 6A), caspase-8, -9, -3 (Fig. 6B), Bax and Bid (Fig. 6C), AIF, Endo G and cytochrome $c$ (Fig. 6D), Fas and FasL (Fig. 6E) and p-ERK and p-p38 (Fig. 6F) but decreased the levels of p-JNK (Fig. 6F) in TSGH 8301 cells leading to apoptosis. Thus, we suggest that NCTD-induced apoptosis is mediated by the mitochondrial and ROS-induced ER stress pathways.

Effects of NCTD on the apoptosis-associated protein translocation in TSGH 8301 cells. In order to confirm that NCTD affected the apoptosis-associated protein translocation in TSGH 8301 cells, $5 \times 10^{4}$ cells/well were plated on 4 -well chamber slides, were then treated with $20 \mu \mathrm{M}$ NCTD for $24 \mathrm{~h}$ and then stained by primary and secondary antibodies and 
A

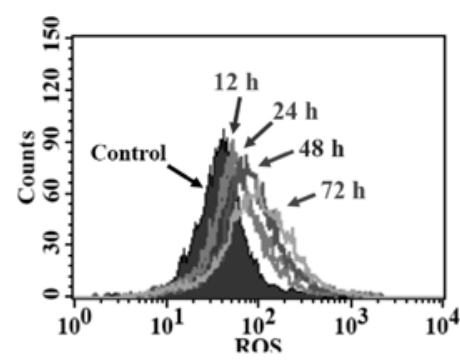

B

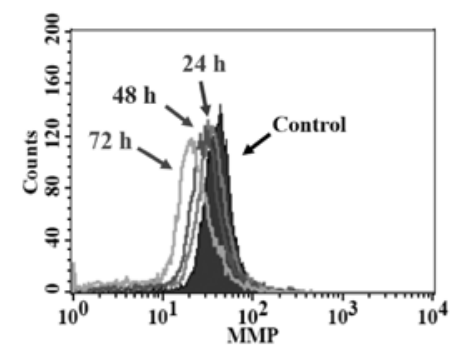

C

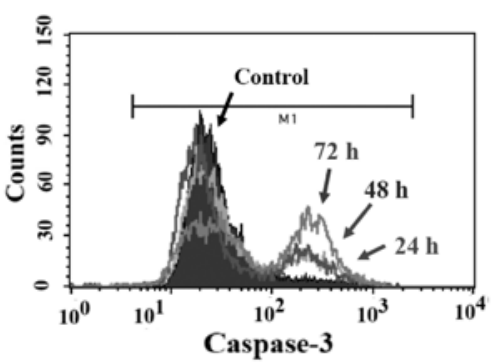

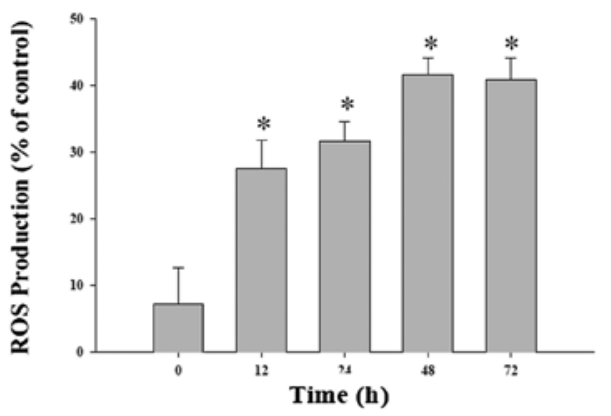
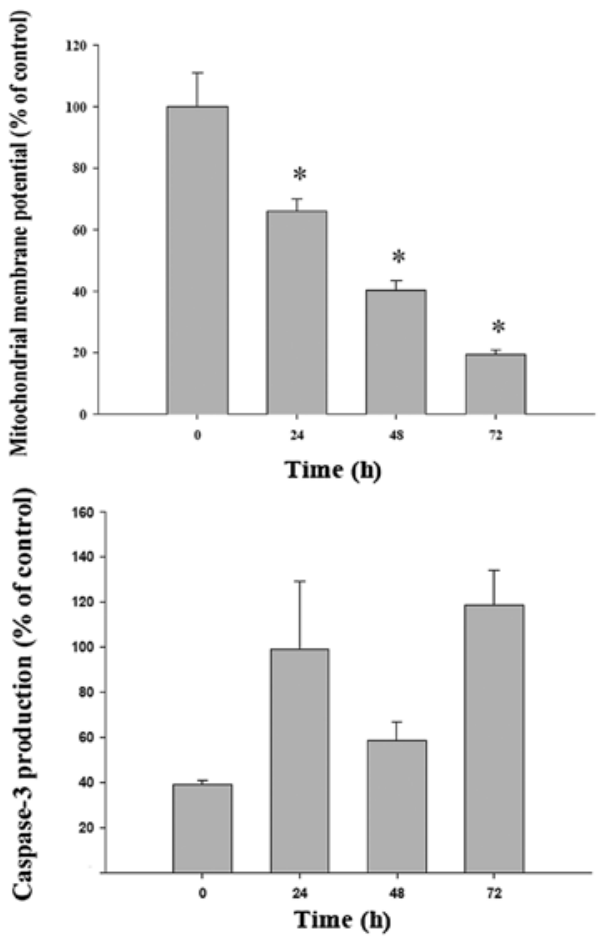

Figure 4. NCTD induced reactive oxygen species (ROS) production, decreased the levels of mitochondrial membrane potential $\left(\Delta \Psi_{m}\right)$ and induced caspase-3 activation in TSGH 8301 cells. Cells $\left(2 \times 10^{5}\right.$ cells $\left./ \mathrm{ml}\right)$ were treated with $20 \mu \mathrm{M}$ of NCTD for different time periods. Cells were harvested for the percentage of (A) ROS, (B) $\Delta \Psi_{m}$, and (C) caspase-3 activity that were stained by DiOC 6 , DCFH-DA, and PhiPhiLux-G1D2, respectively. The stained cells were determined by flow cytometry as described in the Materials and methods. Values are the means $\pm \mathrm{SD}(\mathrm{n}=3)$. ${ }^{*} \mathrm{P}<0.05$ indicates a statistically significant difference from the $0 \mathrm{~h}$ treatment (control group).
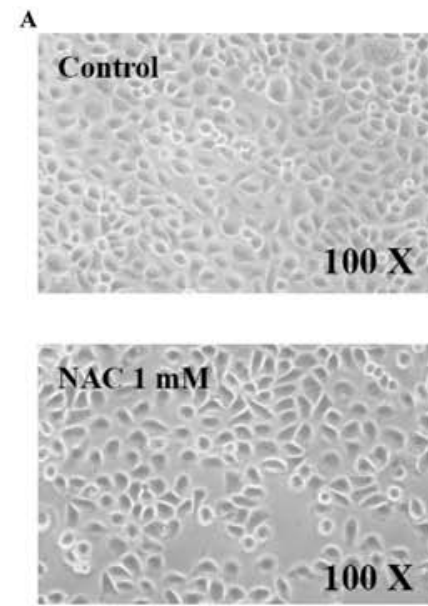
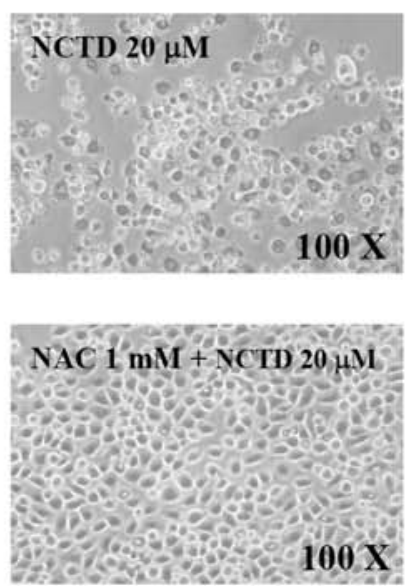

B

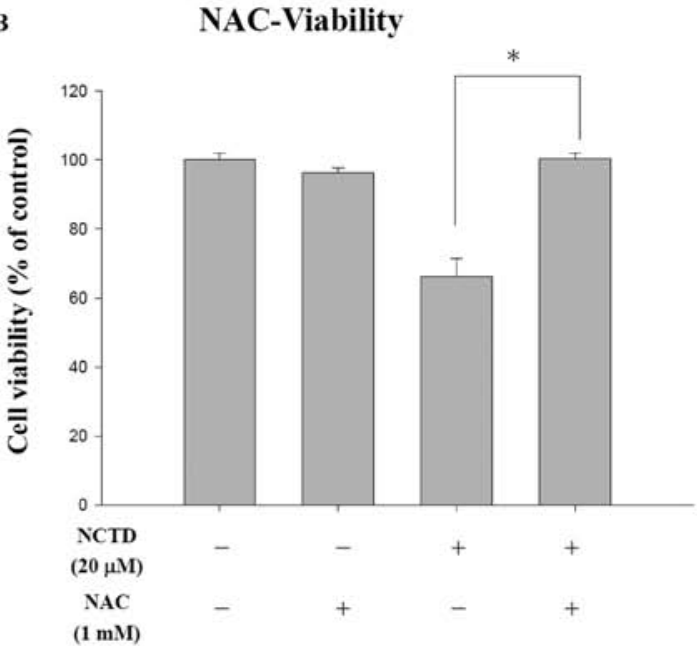

Figure 5. NAC pretreatment affects NCTD induced morphological changes, viability, reactive oxygen species (ROS) production, the levels of mitochondrial membrane potential $\left(\Delta \Psi_{m}\right)$ and NAO and catalase productions in TSGH 8301 cells. Cells $\left(2 \times 10^{5} \mathrm{cell} / \mathrm{s} / \mathrm{ml}\right)$ were pretreated with NAC and were then treated with $20 \mu \mathrm{M}$ of NCTD for different time periods. Cells were (A) examined and photographed for morphological changes and then (B) harvested for the percentage of viable cells. The stained cells were determined by flow cytometry as described in the Materials and methods. Values are the means $\pm \mathrm{SD}(\mathrm{n}=3)$. ${ }^{*} \mathrm{P}<0.05$ indicates a statistically significant difference from the $0 \mathrm{~h}$ treatment (control group). 
C

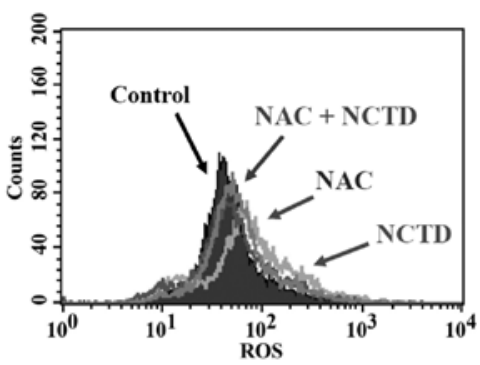

D

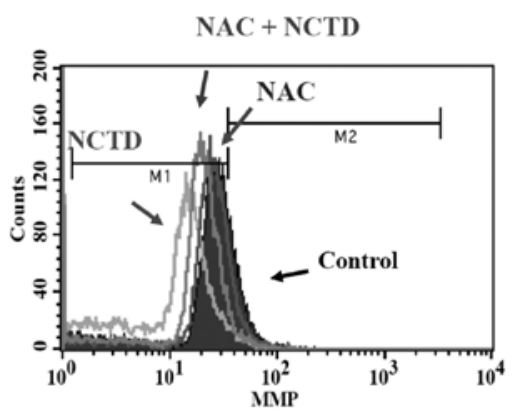

E

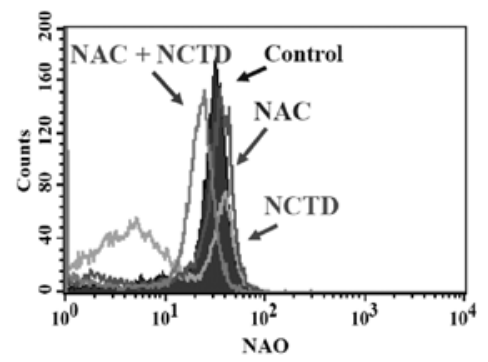

$\mathbf{F}$

Incubation Time (H)

$\begin{array}{llllll}0 & 6 & 12 & 24 & 48 & 72\end{array}$

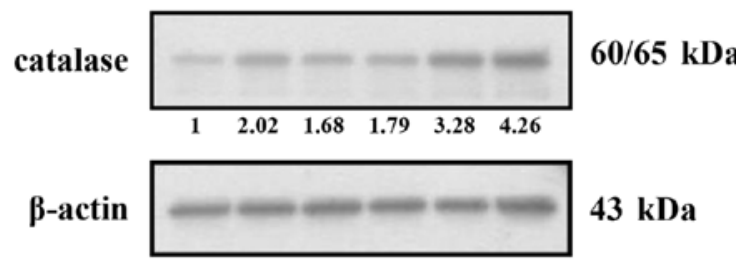

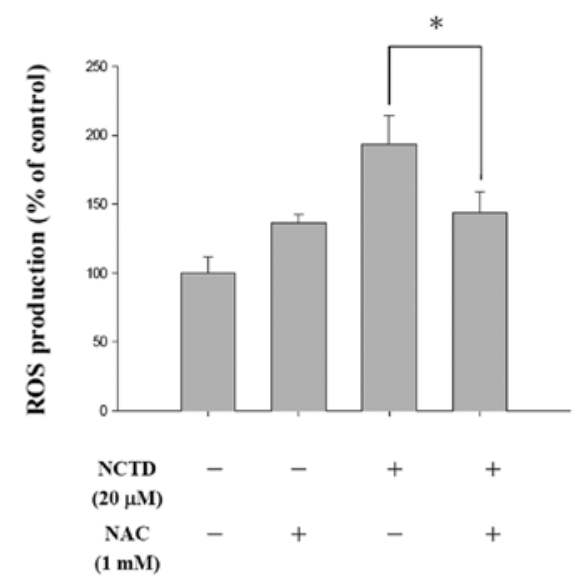
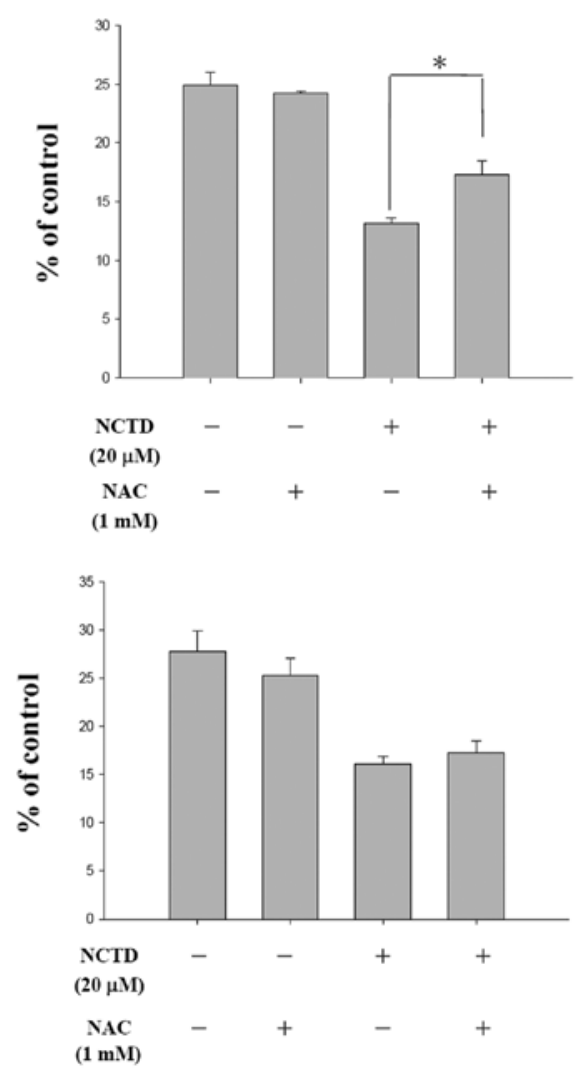

Figure 5. Continued. NAC pretreatment affects NCTD induced morphological changes, viability, reactive oxygen species (ROS) production, the levels of mitochondrial membrane potential $\left(\Delta \Psi_{m}\right)$ and NAO and catalase productions in TSGH 8301 cells. Cells $\left(2 \times 10^{5} \mathrm{cell} / \mathrm{ml}\right)$ were pretreated with NAC and were then treated with $20 \mu \mathrm{M}$ of NCTD for different time periods. Cells were harvested for the (C) percentage of ROS production, (D) levels of $\Delta \Psi_{m}$, and (E) NAO production. The stained cells were determined by flow cytometry as described in Materials and methods. (F) Cells were examined for catalase expression by western blotting. Values are the means $\pm \operatorname{SD}(n=3)$. ${ }^{*} \mathrm{P}<0.05$ indicates a statistically significant difference from the $0 \mathrm{~h}$ treatment (control group).

to orange, indicating that the proteins have migrated to the nuclei. Furthermore, based on the double immuno-fluorescence labelling it was confirmed by means of confocal scanning microscopy that the Endo G and AIF were increased following exposure to NCTD in TSGH 8301 cells. examined and photographed by confocal laser microscopic systems. The results are presented in Fig. 7A and B, the photographs demonstrate that after the merge, Endo G (Fig. 7A) and AIF (Fig. 7B) are released from mitochondria, then translocate to the nuclei evidenced by the nuclei colors already changing 
A

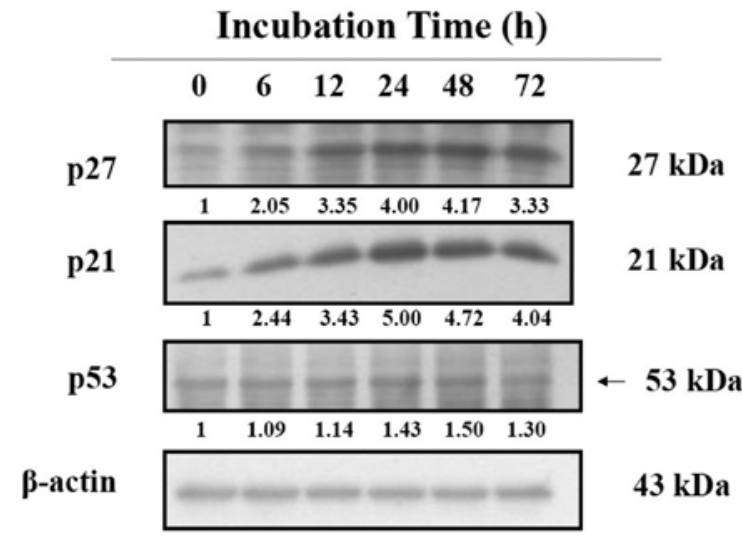

c Incubation Time (h)

$\begin{array}{llllll}0 & 6 & 12 & 24 & 48 & 72\end{array}$

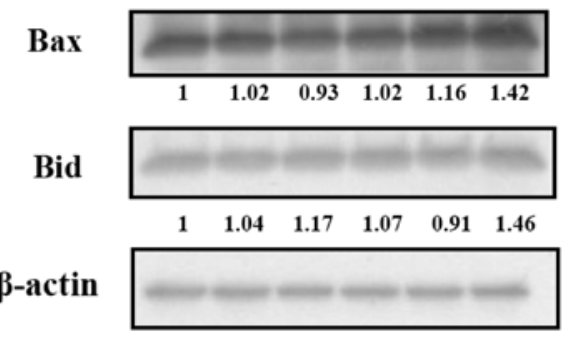

22 kDa

$22 \mathrm{kDa}$

$43 \mathrm{kDa}$

$\mathbf{E}$

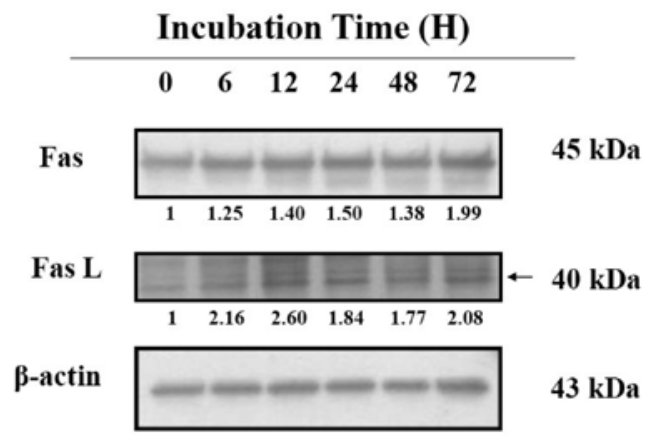

B

Incubation Time (h)

$\begin{array}{llllll}0 & 6 & 12 & 24 & 48 & 72\end{array}$

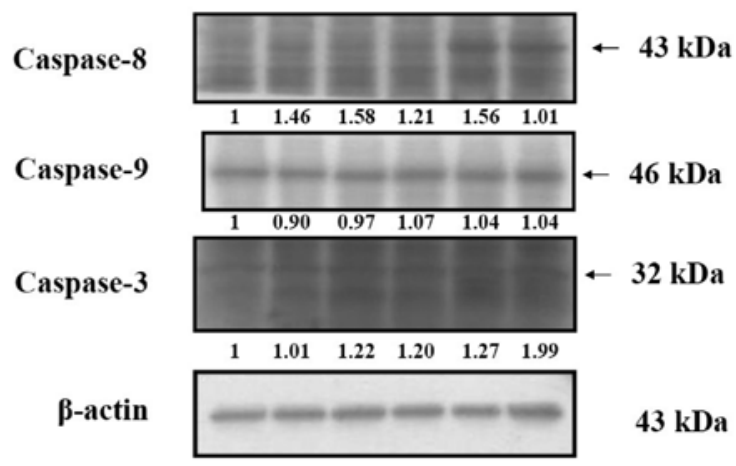

D

Incubation Time (h)

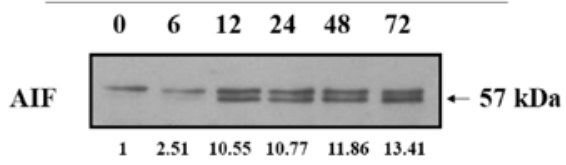

Endo G

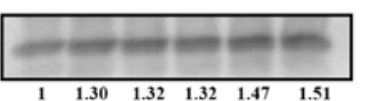

$30 \mathrm{kDa}$

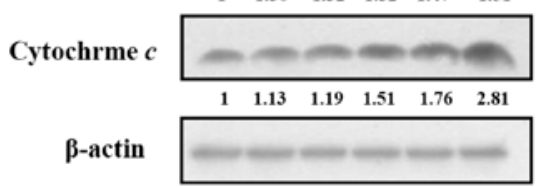

$15 \mathrm{kDa}$

43 kDa

F

Incubation Time (h)

$\begin{array}{llllll}\text { 0 } & 6 & 12 & 24 & 48 & 72\end{array}$

p-ERK 1/2

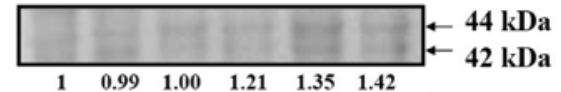

JNK 1/2

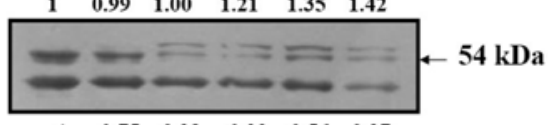

p-p38

$\begin{array}{llllll}1 & 0.75 & 0.23 & 0.22 & 0.56 & 0.27\end{array}$

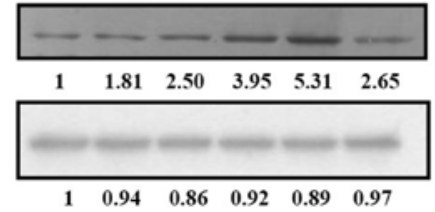

$38 \mathrm{kDa}$

$43 \mathrm{kDa}$

Figure 6. NCTD affected the protein levels of $\mathrm{G}_{0} / \mathrm{G}_{1}$ arrest and apoptosis in TSGH 8301 cells. Cells were treated with $20 \mu \mathrm{M}$ of NCTD for $0,6,12,24,48$ and $72 \mathrm{~h}$ and then total proteins were prepared and detected by western blotting, as described in Materials and methods. Primary antibodies for (A) p27, p21 and p53; (B) caspase-8, -9 and -3; (C) Bax and Bid; (D) AIF, Endo G and cytochrome $c$; (E) Fas and FasL; (F) p-ERK, JNK and p-p38 were examined.

\section{Discussion}

We present results from several observations, demonstrating that NCTD induces apoptosis in TSGH 8301 bladder cancer cells and also show its possible associated mechanism. TSGH 8301 cells treated with NCTD displayed PI- or DAPI-stained condensed nuclei and a sub-G1 DNA phase of PI-stained nuclei analyzed by flow cytometry. Fig. 2 indicates that the number of S-phase cells increased when the number of apoptotic cells increased, as a result of treatment with NCTD. However, there was an apparent decrease in the number of $G_{0} / G_{1}$ and $G_{2} / M$ phase cells within $72 \mathrm{~h}$. With an increase in the NCTD treatment time, the number of $\mathrm{G}_{0} / \mathrm{G}_{1}$ and $\mathrm{G}_{2} / \mathrm{M}$ phase cells gradually decreased and the Sub-G $\mathrm{G}_{1}$ cells increased (Fig. 2A and B). This is not in agreement with other reports demonstrating that NCTD may cause rapid apoptosis in S-phase cells and delayed apoptosis in $\mathrm{G}_{2} / \mathrm{M}$ arrested cells of colorectal cancer cells (9) due to the differences of cancer cells.

The results of this study show that NCTD decreased viable cells and induced S-phase arrest (Fig. 2). Fig. 6A also shows that NCTD increased the levels of p53, p27 and p21 that may lead to S-phase arrest. NCTD induced apoptosis based on DAPI-staining and Sub- $\mathrm{G}_{1}$ phase in cell cycle analysis of TSGH 8301 cells. Flow cytometric assay also showed NCTD promoted caspase-3 activation (Fig. 4C) that was confirmed by western blotting (Fig. 6B) demonstrating that NCTD promoted 

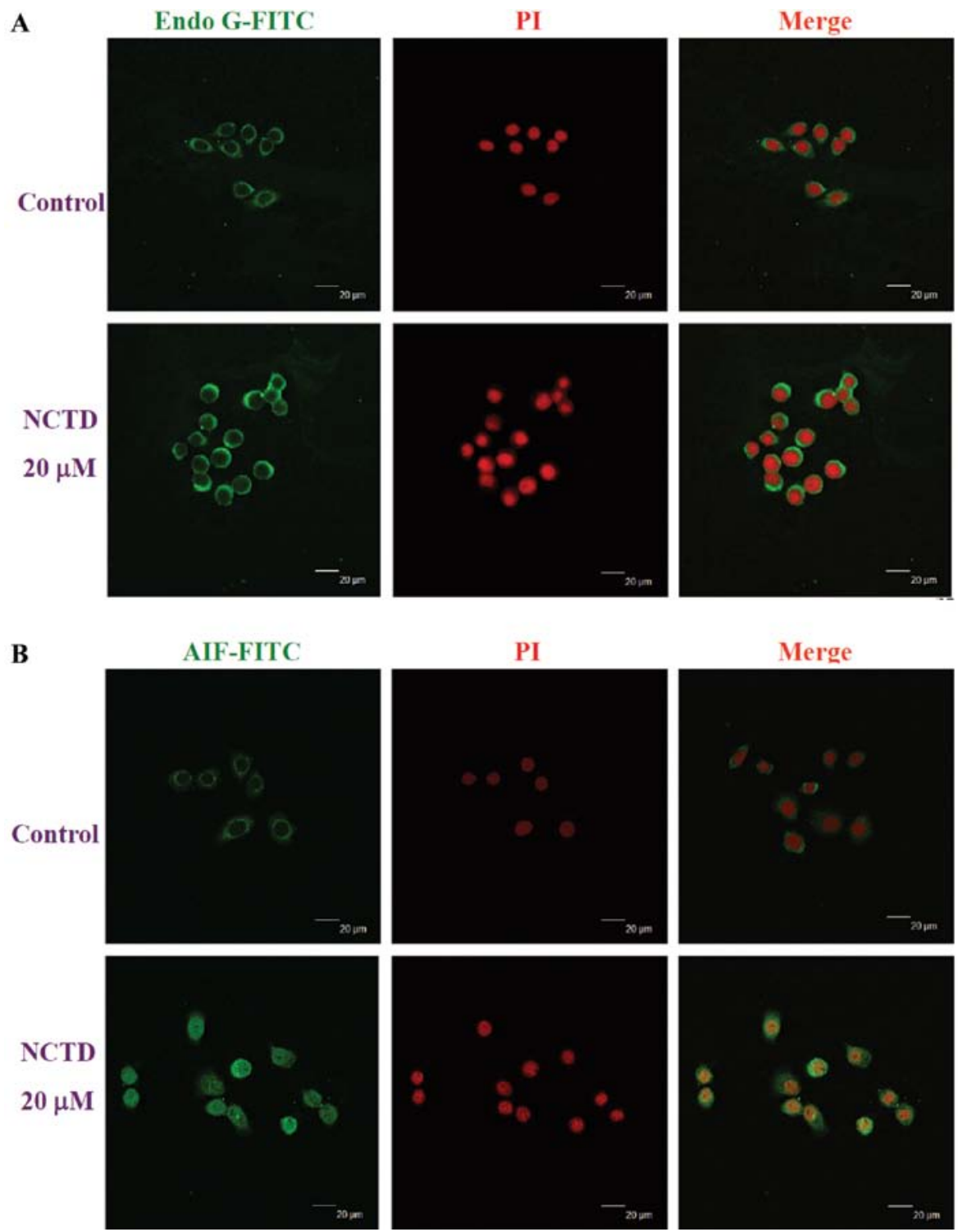

Figure 7. NCTD affected Endo G and AIF distribution in TSGH 8301 cells. Cells were incubated with $20 \mu \mathrm{M}$ NCTD for $24 \mathrm{~h}$ and then fixed and stained with primary antibodies to (A) Endo G and (B) AIF before FITC-labeled secondary antibodies were used (green fluorescence) and the proteins were detected by a confocal laser microscopic system as described in Materials and methods. The nuclei were stained by PI (red fluorescence). Areas of colocalization between AIF and Endo G expression and the nuclei in the merged panels are yellow. Scale bar, $20 \mu \mathrm{m}$.

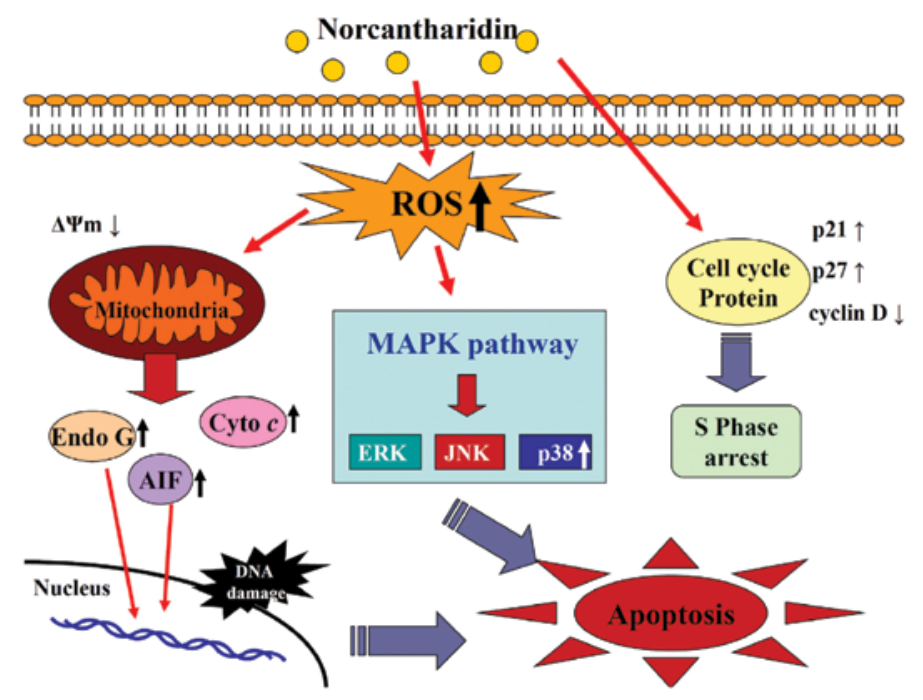

Figure 8. The proposed model of molecular signal pathways from TSGH 8301 cells following exposure to norcantharidin. 
activist form of caspase-8, caspase-3 and caspase-9 (Fig. 6B). It is well known that apoptosis can be divided into caspasedependent- and -independent signal pathways $(22,23)$. Thus, the NCTD induced apoptosis in TSGH 8301 cells was via the caspase-dependent pathway. It has been reported that Fas and Fas ligand activation are involved in drug-induced apoptosis in solid cancer and leukemia cell lines (24). Our results from western blotting (Fig. 6C) indicate that NCTD promoted Fas and FasL in TSGH 8301 cells. NCTD-induced apoptosis may be through the Fas and FasL pathway. This is in agreement with other reports demonstrating that NCTD-treated cells show the activation of caspase- 8 , which has been found to be a prominent signaling caspase involved in the initiation of apoptosis by CD95 $(9,25,26)$.

Flow cytometric assay also showed that NCTD promoted ROS production and decreased the levels of $\Delta \Psi_{m}$ (Fig. 4A and B). This is in agreement with another study indicating that NCTD induced cytotoxicity in human liver cancer HepG2 cells by apoptosis, which is mediated through ROS generation and the mitochondrial pathway (13). It has been reported that agents decreased the levels of $\Delta \Psi_{m}$ which may lead to apoptosis in cancer cells through the mitochondria-dependent pathway (13) which are involved in AIF, Endo G release from mitochondria and lead to apoptosis via the caspase-independent pathway (27). Herein, our results also show that NCTD promoted the expression of AIF and Endo G (Fig. 6D) as confirmed by the confocal laser system microscope (Fig. 7A and B). These novel findings may suggest that NCTD-induced apoptosis in TSGH 8301 cells may occur via the caspase-dependent, -independent and mitochondrialdependent pathways. Our results show that NCTD promoted Bax and BID levels (Fig. 6E). Numerous studies have shown that some Bax, Bcl-XL, Mcl-1, Bcl-2, and Bid are located on the mitochondrial membrane; they can alter the permeability of the mitochondrial membrane causing the activation of caspases leading to apoptosis (28-30). This is in agreement with other reports that show that NCTD inhibited the in vitro and ex vivo growth of human lung cancer A549 cells and regulated the expression of $\mathrm{Bcl}-2$ and $\mathrm{Bax}$ proteins in a dosedependent manner (14).

Our results in Fig. 4A show that NCTD promoted the production of ROS in TSGH 8301 cells. Furthermore, pretreatment of cells with NAC followed by NCTD led to NCTD-induced increase in ROS that can be abolished or attenuated by NAC (antioxidant). This is in agreement with other reports indicating that the NCTD-induced increase in ROS and anti-proliferation of human liver cancer HepG 2 cells are apparently dependent on ROS generation (14). Thus, in the present study, our results demonstrate that NCTD promotes ROS production and a decrease in the levels of $\Delta \Psi_{m}$, leading to apoptosis. Other reports have shown that cancer cells after being exposed to anticancer agents led to the generation of ROS contributing to mitochondrial damage and then leading to cell death by acting as an apoptotic signaling molecule $(31,32)$. In the present study, ERK, JNK, and p38 were all found to be activated in TSGH 8301 cells following exposure to NCTD. Thus, NCTD-induced cytotoxicity could be due to the induced JNK activation in TSGH 8301 cells.

In conclusion, based on the above results NCTD efficiently inhibited the growth of TSGH 8301 human bladder cancer cells via the Fas receptor leading to caspase-3 activation for apoptosis known as mitochondria-independent and to other pathways through mitochondria-dependent signal pathways to the release of AIF and Endo G causing apoptosis. The possible signal pathways of NCTD-induced apoptosis in TSGH 8301 cells is shown in Fig. 8. Further investigation on both in vivo and in vitro bladder cancer models is required.

\section{Acknowledgements}

This work was supported by a research grant (CMU100-S-14) from China Medical University, Taichung, Taiwan and the grant-in-aid from the National Science Council, Republic of China (Taiwan) (NSC 99-2815-C-039-053-B).

\section{References}

1. Chen RJ, Ho CT and Wang YJ: Pterostilbene induces autophagy and apoptosis in sensitive and chemoresistant human bladder cancer cells. Mol Nutr Food Res 54: 1819-1832, 2010.

2. Singh RP, Dhanalakshmi S and Agarwal R: Phytochemicals as cell cycle modulators - a less toxic approach in halting human cancers. Cell Cycle 1: 156-161, 2002.

3. Degterev A, Boyce M and Yuan J: A decade of caspases. Oncogene 22: 8543-8567, 2003.

4. Ziegler DS and Kung AL: Therapeutic targeting of apoptosis pathways in cancer. Curr Opin Oncol 20: 97-103, 2008.

5. Klein S, McCormick F and Levitzki A: Killing time for cancer cells. Nat Rev Cancer 5: 573-580, 2005.

6. Kao ST, Yeh CC, Hsieh CC, et al: The Chinese medicine $\mathrm{Bu}-$ Zhong-Yi-Qi-Tang inhibited proliferation of hepatoma cell lines by inducing apoptosis via G0/G1 arrest. Life Sci 69: 1485-1496, 2001.

7. Gamet-Payrastre L, Li P, Lumeau S, et al: Sulforaphane, a naturally occurring isothiocyanate, induces cell cycle arrest and apoptosis in HT29 human colon cancer cells. Cancer Res 60: 1426-1433, 2000.

8. Wang GS: Medical uses of mylabris in ancient China and recent studies. J Ethnopharmacol 26: 147-162, 1989.

9. Peng F, Wei YQ, Tian L, et al: Induction of apoptosis by norcantharidin in human colorectal carcinoma cell lines: involvement of the CD95 receptor/ligand. J Cancer Res Clin Oncol 128: 223-230, 2002.

10. Huang Y, Liu Q, Liu K, Yagasaki K and Zhang G: Suppression of growth of highly-metastatic human breast cancer cells by norcantharidin and its mechanisms of action. Cytotechnology 59: 209, 2009.

11. Chen YN, Chen JC, Yin SC, et al: Effector mechanisms of norcantharidin-induced mitotic arrest and apoptosis in human hepatoma cells. Int J Cancer 100: 158-165, 2002.

12. Fan YZ, Zhao ZM, Fu JY and Chen CQ: Anti-tumor mechanism of norcantharidin for the implanted tumors of human gallbladder carcinoma in nude mice in vivo. Zhonghua Wai Ke Za Zhi 44: 618-622, 2006 (In Chinese).

13. Chang C, Zhu YQ, Mei JJ, Liu SQ and Luo J: Involvement of mitochondrial pathway in NCTD-induced cytotoxicity in human hepG2 cells. J Exp Clin Cancer Res 29: 145, 2010.

14. Luan J, Duan H, Liu Q, Yagasaki K and Zhang G: Inhibitory effects of norcantharidin against human lung cancer cell growth and migration. Cytotechnology 62: 349-355, 2010.

15. Chen YJ, Tsai YM, Kuo CD, Ku KL, Shie HS and Liao HF: Norcantharidin is a small-molecule synthetic compound with anti-angiogenesis effect. Life Sci 85: 642-651, 2009.

16. Kok SH, Cheng SJ, Hong CY, et al: Norcantharidin-induced apoptosis in oral cancer cells is associated with an increase of proapoptotic to antiapoptotic protein ratio. Cancer Lett 217: 43-52, 2005.

17. Kok SH, Hong CY, Kuo MY, et al: Comparisons of norcantharidin cytotoxic effects on oral cancer cells and normal buccal keratinocytes. Oral Oncol 39: 19-26, 2003.

18. Peng C, Liu X, Liu E, et al: Norcantharidin induces HT-29 colon cancer cell apoptosis through the alphavbeta6-extracellular signal-related kinase signaling pathway. Cancer Sci 100: 2302-2308, 2009. 
19. Lu CC, Yang JS, Huang AC, et al: Chrysophanol induces necrosis through the production of ROS and alteration of ATP levels in J5 human liver cancer cells. Mol Nutr Food Res 54: 967-976, 2010.

20. Chiang JH, Yang JS, Ma CY, et al: Danthron, an anthraquinone derivative, induces DNA damage and caspase cascades-mediated apoptosis in SNU-1 human gastric cancer cells through mitochondrial permeability transition pores and Bax-triggered pathways. Chem Res Toxicol 24: 20-29, 2011.

21. Kuo JH, Chu YL, Yang JS, et al: Cantharidin induces apoptosis in human bladder cancer TSGH 8301 cells through mitochondriadependent signal pathways. Int J Oncol 37: 1243-1250, 2010.

22. Saile B, Eisenbach C, El-Armouche H, Neubauer K and Ramadori G: Antiapoptotic effect of interferon-alpha on hepatic stellate cells (HSC): a novel pathway of IFN-alpha signal transduction via Janus kinase 2 (JAK2) and caspase-8. Eur J Cell Biol 82: 31-41, 2003.

23. Lee YJ, Song JJ, Kim JH, Kim HR and Song YK: Low extracellular $\mathrm{pH}$ augments TRAIL-induced apoptotic death through the mitochondria-mediated caspase signal transduction pathway. Exp Cell Res 293: 129-143, 2004.

24. Kikuchi T, Akazawa H, Tabata K, et al: 3-O-(E)-p-coumaroyl tormentic acid from Eriobotrya japonica leaves induces caspasedependent apoptotic cell death in human leukemia cell line. Chem Pharm Bull (Tokyo) 59: 378-381, 2011.

25. Glick RD, Swendeman SL, Coffey DC, et al: Hybrid polar histone deacetylase inhibitor induces apoptosis and CD95/CD95 ligand expression in human neuroblastoma. Cancer Res 59: 4392-4399, 1999.
26. Boldin MP, Goncharov TM, Goltsev YV and Wallach D: Involvement of MACH, a novel MORT1/FADD-interacting protease, in Fas/APO-1- and TNF receptor-induced cell death. Cell 85: 803-815, 1996.

27. Liu KC, Huang YT, Wu PP, et al: The roles of AIF and Endo G in the apoptotic effects of benzyl isothiocyanate on DU 145 human prostate cancer cells via the mitochondrial signaling pathway. Int J Oncol 38: 787-796, 2011.

28. Huan SK, Lee HH, Liu DZ, Wu CC and Wang CC: Cantharidininduced cytotoxicity and cyclooxygenase 2 expression in human bladder carcinoma cell line. Toxicology 223: 136-143, 2006.

29. Rauh R, Kahl S, Boechzelt H, Bauer R, Kaina B and Efferth T: Molecular biology of cantharidin in cancer cells. Chin Med 2: 8, 2007.

30. Adams JM and Cory S: The Bcl-2 protein family: arbiters of cell survival. Science 281: 1322-1326, 1998.

31. Zhang R, Humphreys I, Sahu RP, Shi Y and Srivastava SK: In vitro and in vivo induction of apoptosis by capsaicin in pancreatic cancer cells is mediated through ROS generation and mitochondrial death pathway. Apoptosis 13: 1465-1478, 2008.

32. Ott M, Gogvadze V, Orrenius S and Zhivotovsky B: Mitochondria, oxidative stress and cell death. Apoptosis 12: 913-922, 2007. 